\title{
The feasibility of vocational rehabilitation in subjects with severe mental illness
}

\author{
Stefan Watzke, Dr Rer Nat, ${ }^{(1)}$ Anja Galvao, DP.(I)
}

\author{
Watzke S, Galvao A. \\ The feasibility of vocational rehabilitation \\ in subjects with severe mental illness. \\ Salud Publica Mex 2008;50 suppl 2:S260-S272.
}

\section{Watzke S, Galvao A.}

Factibilidad de la rehabilitación vocacional en personas con enfermedades mentales graves. Salud Publica Mex 2008;50 supl 2:S260-S272.

\section{Resumen}

La rehabilitación vocacional representa un importante elemento dentro del sistema del cuidado de la salud mental. Con el fin de asegurar el éxito de la rehabilitación y para satisfacer las necesidades y habilidades de los pacientes hacen falta programas de diversos grados de complejidad. El resultado de la rehabilitación debe examinarse de manera multidimensional y no reducirse tan sólo a la integración al empleo competitivo, pues el éxito se ve reflejado asimismo por el avance en el nivel de integración vocacional, el fortalecimiento de las capacidades para el trabajo, la mejora del nivel de funcionamiento y una mejor calidad de vida. Las necesidades de rehabilitación del paciente deben reconocerse tan pronto como sea posible para disminuir la desintegración y para evitar periodos de estancamiento. La rehabilitación debe comenzar en la clínica, con apoyo psiquiátrico sostenido durante el proceso a fin de evitar la exacerbación de la enfermedad y una terminación prematura del programa. El desarrollo del paciente en lo concerniente a nivel de funcionamiento, capacidad de trabajo y bienestar subjetivo requiere de constante evaluación a lo largo del programa a fin de monitorear sus necesidades y habilidades individuales y para asegurar el apoyo correcto. El entrenamiento cognoscitivo y de habilidades sociales debe integrarse en los programas de rehabilitación para compensar las carencias individuales.

Palabras clave: rehabilitación vocacional; resultado funcional; reintegración; trastornos mentales graves reintegration; severe mental disorders

(I) Department of Psychiatry and Psychotherapy, Martin-Luther University Halle-Wittenberg 06097 Halle/Saale, Germany. 
Severe mental illnesses show numerous characteristics that are extremely limiting to a successful career. Even the mere presence of psychiatric symptoms (e.g. depression that prevents the patient from leaving bed to go to work; delusions that may disturb social work relations) cuts the probability of being competitively employed. Patients experience their own disabilities and realize that the psychiatric disorder they suffer from limits their occupational achievements. ${ }^{1}$ Indeed, patients with severe mental disorders are likely to have serious functional impairments which may lead to the loss of their jobs and social withdrawal. Beiser and coworkers ${ }^{2}$ conclude that occupational descent is not only common for patients suffering from schizophrenia but also for patients with mood disorders. Functional impairments resulting from mental disorders can endure for years without improvement, ${ }^{3}$ and functional recovery often lags behind symptomatic recovery and may still be incomplete even when acute symptoms have subsided. ${ }^{4,5}$

Only about 10 to $20 \%$ of the mentally ill are competitively employed. ${ }^{6}$ Competitive employment is not only crucial for independent living, but also for social appreciation, integration into society, and reduction of illness-related stigmata. ${ }^{7}$ Loss or absence of employment not only leads to deterioration of the individual's material situation but also to aggravation of the mental illness. ${ }^{8}$ In schizophrenia patients, unemployment is associated with an increase of negative symptoms. ${ }^{9}$ For subjects without mental disorders, studies reported that unemployment promotes suicidal tendencies ${ }^{10}$ and increased rates of depression. ${ }^{11}$

When patients with severe mental illnesses are permanently excluded from employment early on in their career, they depend on permanent disability payments. However, in most cases, they have contributed to social pension funds only for a short period of time. Thus, by and large they can only expect modest payments from these funds. In fact, obtaining monetary support from pension funds, in some cases secures financial survival but for the majority, depending on these payments means impoverishment. ${ }^{12}$

Vocational rehabilitation for people with severe mental illness comprises all systematic and organized efforts of support of psychiatric patients and their integration into occupations, apprenticeships and employment. ${ }^{13}$ Vocational rehabilitation aims towards increased participation in society. The primary means to reach this goal is reintegration into employment. Employment itself is proposed to have positive effects on the course of the illness because integration into work supplies the opportunity of personal success through mastering external demands. Beyond financial remuneration as a basis for a self-determined life, employment promotes the fulfilling of normal social roles and counteracts a role of being chronically ill. Moreover, being able to work is a criterion of convalescence and makes it possible to achieve social status and identity. Additionally, being integrated into employment structures the daily schedule and helps to establish social networks and support.

\section{Vocational rehabilitation approaches}

Theoretically, the whole spectrum of work, apprenticeship, and employment is accessible for patients with severe mental disorders. The beneficial effects of employment to mental health have been known for a long time. Thus, efforts to integrate psychiatric patients into work and employment have been an essential element of psychiatric rehabilitation since its beginning. Today, the system of vocational support for psychiatric patients comprises a multitude of rehabilitation approaches. These approaches cover a broad field of activities from "choosing an appropriate job" over "getting an appropriate job" to "keeping an appropriate job" for the patients. ${ }^{13}$ Psychiatric rehabilitation comprises two fundamental intervention strategies: ecological strategies are directed towards developing environmental resources to reduce potential stressors. ${ }^{14}$ Facilities of day care, sheltered living, and sheltered workplaces in the community promote processes of individual learning and development and supply an environment in which the patient can live and work with his or her capabilities. Individual-centered approaches, on the other hand, aim at developing the patient's skills to interact with a stressful work environment. Individual-centered vocational rehabilitation programs can be classified as follows: a) hospital-based programs; b) sheltered work; c) psychosocial rehabilitation, including prevocational training and transitional employment; d) supported employment.

In hospital-based programs, psychiatrists, psychologists, and social workers are responsible for identifying the patient's needs for achieving vocational rehabilitation as early as possible in the course of the illness. Beginning with the patient's stay in the hospital, first diagnostics of work capabilities and individual needs should lead to prospects and planning for further rehabilitation support. Particularly, after longer periods of unemployment, hospital work therapy can initially promote the reinforcement of basic work skills. ${ }^{15}$ According to individual needs and capabilities based on diagnostic information from this early stage, caregivers choose the appropriate rehabilitation program for the patient. 
Community-based vocational rehabilitation programs provide a series of steps to endorse job entry or re-entry. Sheltered workshops offer employment opportunities for patients with the most severe disabilities. The patients can undertake meaningful paid employment under supportive conditions. Even though sheltered workshops also provide pre-vocational training, in most cases the disabled person reaches a dead end in rehabilitation. Therefore, sheltered workshops play a limited role in modern rehabilitation concepts for people with mental disorders. In North America, the 'clubhouse' model emerged as a development of the sheltered workshop. It aims at support and preparation for employment. Patients are seen as Clubhouse Members and have the possibility to participate in the organization of the house. They share responsibility with staff for maintaining the building, preparing meals, and working in the office. After a period of prevocational training, employment placements are arranged in a variety of temporary jobs with mainstream employers, the employment contract being held by the clubhouse organization and shared between members. ${ }^{16}$ Unfortunately, in many cases, these shared job placements are limited to unskilled, low-grade positions. ${ }^{17}$

Psychosocial rehabilitation programs comprise psychiatric services as well as psychotherapeutic support and work therapy. Social skills training and pre-vocational training are also integral components under supportive work conditions. Within the rehabilitation process, realistic goals are developed with the patient regarding his social and vocational future. Participants receive classes in work related topics such as mathematics, basic computer skills, administration or bookkeeping, metal crafts or woodwork. Brief and focused techniques are applied to teach how the patients can find a job in the open job market, fill out applications and conduct employment interviews. Depending on individual needs regarding social, interactional and vocational problems, courses are put together for training in social communication and competence, concentration and memory as well as daily management. Leisure activities during free time can complement the program. In the course of rehabilitation, demands are qualitatively and quantitatively increased in a stepwise manner, supplemented by courses in stress relief and relaxation. Medical and psychotherapeutic treatment and social support are integrated elements of the program.

In transitional employment, a temporary work environment is provided to teach vocational skills which should enable the affected person to move on to competitive employment. The uppermost aim is the patients' integration into work according to their individual needs and skills. But all too often the gap between transitional and competitive employment is too wide, so that the mentally disabled individuals remain in a temporary work environment. ${ }^{16}$

The most promising vocational rehabilitation model today is supported employment (SE). ${ }^{18}$ With respect to their choices and capabilities psychiatric patients are placed in competitive workplaces as soon as possible after entering the program. According to an "individual placement and support model" they receive continued and indefinite support to maintain their position. Participation in SE programs is followed by an increase in the ability to find and keep employment. ${ }^{19}$ Although findings regarding this new approach are encouraging, some critical aspects need to be mentioned. ${ }^{20}$ First, in many cases patients are integrated in unskilled parttime jobs. Second, since studies primarily evaluated short term follow-up periods, the long term outcome still needs to be evaluated.

\section{Success of vocational rehabilitation}

Since the 1970s, numerous evaluation studies in the course of the development of community psychiatric services have been published. Scientific papers mainly addressed two types of research questions: on one hand, the evaluation of the effectiveness of vocational rehabilitation programs; on the other hand, the identification of prognostic factors for prediction of rehabilitation success. Both lines of thought are closely linked and show strong dependencies on basic assumptions about the nature of rehabilitation success. Reviewing the literature, it becomes clear that there is only limited agreement between studies on how to define rehabilitation success. ${ }^{21}$ Thus, it is hardly possible to compare the results of different studies that applied different evaluation criteria. ${ }^{22}$ Therefore, it is necessary to clarify the possible definitions of vocational rehabilitation success.

The main criterion used in studies is the number of patients integrated in competitive work after program termination. Reker ${ }^{13}$ remarks that defining rehabilitation success exclusively by the relative proportion of patients employed has considerable methodological weaknesses, as the research topic "employment" is actually quite complex. Effects and results of work rehabilitation do not depend solely on the individual characteristics of the participating patients or the rehabilitation program, but to a high degree also on regional socio-economic circumstances and limitations of the job market, as has been shown by Morgan and Cheadle. ${ }^{23}$

Moreover, a fundamental difficulty lies in the fact that in some evaluation studies work is simultaneously considered a central part of the rehabilitation program and a therapeutic method as well as the main 
goal of rehabilitation and thus its evaluation criterion. Methodologically speaking, the intervention (e.g. work therapy and transitional employment) does not differ from the intended result of the program (e.g. work under protected conditions). Norquist ${ }^{24}$ stresses the necessity to create specific evaluation criteria for specific interventions, to allow quality comparisons between interventions. Additionally, it is necessary to apply measures which produce sufficient variance within the study population. Therefore, events that are seldom achieved are considered to be insufficient to serve as an evaluation criterion.

Vocational rehabilitation is confronted with the dilemma of trying to integrate psychiatric patients into a work environment that is not even capable of providing employment for all healthy members of society. Today's labor market requires predictability, flexibility, work capability, and qualification of its workforce-characteristics which are sometimes contrary to the skills and abilities of the chronically mentally ill. ${ }^{13}$ High psychological stress resulting from competitive work can lead to a reduction of the functioning level of psychiatric patients. ${ }^{25}$ In unfavorable socio-economic circumstances and fully stretched job markets, rates of successful integration can be classified as seldom events as only modest employment rates are achieved. ${ }^{26} \mathrm{Ad}-$ ditionally, reintegration into competitive employment involves the danger of expecting too much from patients and possibly exposing them to the experience of yet another setback.

Therefore, integration into competitive employment represents only one aspect of rehabilitation success. It seems to be necessary to focus on broader criteria for the evaluation of vocational rehabilitation. For the majority of patients, integration is reached only partially and employment under sheltered conditions should be valued as positive rehabilitation outcome. This was taken in account already by Ciompi, Ague \& Dauwalder ${ }^{27}$ which defined rehabilitation success as a progress on the level of vocational integration, ranging from competitive employment over sheltered work and further rehabilitation. Negative rehabilitation outcome in this sense is represented by unemployment and premature exclusion from work due to early retirement.

An extended description of rehabilitation success should involve the reduction of social and functional impairment as well as different aspects of psychological wellbeing. According to the principles of normalization, rehabilitation is aimed at different areas of functioning and social living, and thus must not be hastily restricted to the mere integration into competitive employment. Evaluation of vocational reintegration should be assessed multidimensionally, ${ }^{26}$ involving measures of vocational integration and progress as well as measures of functional outcome independent from the resulting employment situation. Following this train of thought, success of vocational rehabilitation can be structured as follows. ${ }^{28,29}$

- Traditional evaluation studies of vocational rehabilitation applied normative criteria such as rates of patients competitively employed after program termination.

- According to the rehabilitation principle of normalization of participation in the society, measures of progress on the level of vocational integration serve as evaluation criteria. Additionally, rehabilitation success can be measured by increasing work income and working hours.

- Beyond integration into work, vocational rehabilitation focuses on the reduction of social impairments and imparting of social skills. In this context, increased levels of functioning and decreased levels of social impairments can be used as evaluation criteria.

- Patient-reported outcome measures are increasingly considered to be of importance for the evaluation of mental health care in general. They reflect the "patient needs and values". ${ }^{30}$ Various constructs have been established to capture patient-reported outcomes, most notably self-ratings of symptoms, subjective quality of life, and needs.*

- A theory-based approach of rehabilitation success is represented by the evaluation of work capabilities. Those measures depict the individual qualification to fulfill the demands of employed work.

In the next section, these evaluation criteria will be differentiated more clearly and relevant empirical findings will be discussed.

\section{Evaluation and prediction of employment rates}

Vocational rehabilitation programs increase the rate of competitive employment in patients with severe mental illness. ${ }^{26}$ However, current rehabilitation programs achieve only modest employment rates of about 15-30\% among psychiatric populations. And even these mod-

\footnotetext{
* Brieger P, Watzke S, Galvao A, Priebe S. Is there one general subjective appraisal factor underlying different patient-reported outcome measures in long-term rehabilitation? Unpublished document.
} 
est employment rates decrease with each follow-up period. ${ }^{19,31,32}$ These figures are alarming; even more so against the backdrop of the finding that the employment status of psychiatric patients can also change without explicit vocational rehabilitation. In a study by Mueser and coworkers, ${ }^{33}$ after a first illness episode $9.7 \%$ of patients with schizophrenia were competitively employed. One year later, $23.3 \%$ of the patients were employed without participation in a rehabilitation program. More than $13 \%$ of the patients were able to return to work without specific interventions.

Prediction models of successful reintegration into competitive employment are supplied by a great number of studies. Research on schizophrenia identified different clusters of prognostic factors.

At first, variables of premorbid functioning turned out to be predictors of successful reintegration. Good premorbid social functioning, ${ }^{33}$ premorbid intelligence, ${ }^{21}$ education level, ${ }^{13}$ and duration of pre-rehabilitation unemployment ${ }^{34}$ contributed to the prediction of rehabilitation success. On one hand, with regard to their premorbid characteristics these variables withdraw from specific rehabilitation interventions. On the other hand they supply first indications of the importance of rehabilitation within the full spectrum of psychiatric services: rehabilitation must be integrated at a very early stage of intervention to limit unfavorable development during first episodes of the illness. Clinical psychiatrists are needed to recognize individual rehabilitation needs as soon as possible in order to shorten the time span between the first admission to a psychiatric hospital and the start of vocational rehabilitation. The duration of pre-rehabilitation unemployment is an especially valid predictor of rehabilitation success in pointing out that (re-)integration into employment becomes more difficult the longer a patient is unemployed before getting vocational rehabilitation.

A second cluster of possible predictors of successful reintegration consists of illness related variables. Late onset and short illness duration ${ }^{13}$ have a positive influence on successful work integration. The first of these two predictors corroborates the findings described above. The later the onset of the illness, the less likely the impairment in the patient's premorbid development, since the exacerbation of the disease does not limit education level or apprenticeship. A short illness duration as a predicting variable suggests possible influences of a successful rehabilitation. As has already been established herein, rehabilitation must take place as soon as possible within the course of the illness. In addition, this new predictor tells us that rehabilitation must take place as soon as possible within a specific illness episode. A direct transfer of the patient from the clinic to rehabilitation facilities without wide time gaps, will facilitate continuous support that will prevent the patient from returning to possibly unfavorable surroundings without social support and without appropriate work opportunities.

The role of psychopathology in predicting rehabilitation success is controversial. In a very influential review on rehabilitation success by Anthony and Jansen, ${ }^{25}$ the authors assume that the kind of diagnosis, as well as the current psychopathology, have only limited influence on the success of rehabilitation. These findings are confirmed by a meta-analysis by McGurk and Mueser. ${ }^{20}$ These authors summarized the results of studies on integration of psychiatric samples with and without participation in rehabilitation programs. They found correlative associations between general, positive, and negative symptoms and employment. However, the predictive value of symptom status for reintegration was low, especially in prospective studies. Only one out of five studies proved general symptoms to be relevant for the prediction of employment. Positive symptoms had no predictive value. Negative symptoms predicted employment in four out of seven studies. Low levels of negative symptoms had considerable influence on reintegration. ${ }^{15}$ In these authors' work as well as in a study conducted by Brieger et al., ${ }^{34}$ good social and work skills were valuable predictors of successful reintegration into employment. Here, a third cluster of predictors for successful reintegration into work was identified. Good social skills and, specifically, good work skills constantly contributed to a successful rehabilitation. Significant improvement of work skills during rehabilitation is related to higher employment rates after rehabilitation. ${ }^{34,35}$ General work behavior assessed during the rehabilitation process predicted employment status six months after rehabilitation. ${ }^{36}$ Thus, training in social skills and work capabilities should be included as main components of vocational rehabilitation programs, as will be explained later on.

\section{Evaluation and prediction of the progress on the level of vocational integration}

With regard to the low rates of successful reintegration of psychiatric patients into competitive employment, the question arises whether evaluation of vocational rehabilitation should be reduced to mere reintegration rates. Integration into competitive employment represents only one aspect of vocational integration, as already mentioned above.

According to Reker (1998), vocational integration as an evaluation criterion can be differentiated using an ordinal scale containing the following levels. 
1. Competitive employment or regular apprenticeship

2. Work or apprenticeship under protected conditions

3. Continuing vocational rehabilitation for subjects with mental illness

4. Unemployment

5. Permanent disability payments.

This scale takes into account that -under unfavorable economic conditions- vocational integration is often only partially reached through integration in protected work environments or continuing vocational rehabilitation for patients with severe mental illness.

Using this kind of measure, studies allow a better overall view on reintegration success. Beyond integration into competitive employment, differential statements about progress, stagnation, or regression of the patient's vocational integration level are possible. Dauwalder and coworkers ${ }^{37}$ evaluated the rehabilitation efforts of a Swiss university psychiatric clinic and found that $30 \%$ of the patients had an improvement of their vocational integration level compared to their work situation prior to rehabilitation. Reker (1998) elaborated a scale from "unemployment" over "ambulant work therapy or transitional employment", and "work under protected conditions", up to "competitive employment", and evaluated different rehabilitation programs. After rehabilitation in sheltered employment, only $6 \%$ of the patients reached competitive employment; the majority $(80 \%)$ remained in the sheltered workplace; $13 \%$ faced unemployment. Three years after ambulant work therapy, 19\% of the patients found competitive employment, $23 \%$ worked under protected conditions, $22 \%$ remained in the work therapy, and $16 \%$ became unemployed. This method of program evaluation supplies a considerable gain of information beyond the normative rates of employment and therefore allows a better comparison of different rehabilitation approaches.

In regression models, prognostic factors similar to those used in predicting employment rates proved to be relevant. Again, premorbid intelligence, social integration, and a low duration of disintegration had prognostic validity in predicting the level of vocational integration. ${ }^{37}$ In a study by Hoffmann and coworkers ${ }^{21}$ improvement in the level of vocational integration was prospectively predicted by negative symptoms, intelligence, functional impairment, locus of control, and cognitive performance. The predictors explained 30\% of the variance.

\section{Evaluation and prediction of the functional level}

Vocational rehabilitation can be seen as a supporting process for the transition to a higher level of social independence. ${ }^{38}$ Therefore, it is essential to consider an improvement of the general functional level and a decrease of functional impairment as important criteria of rehabilitation success. If evaluation of rehabilitation only focuses on fundamental vocational domains, other aspects of the intervention are automatically neglected and the effectiveness of rehabilitation is underestimated. Improvement of functional impairment during rehabilitation was shown by Ferdinandi, Yoottanasumpun, Pollack and Bermanzohn, ${ }^{39}$ as well as in a study by Hoffmann and Kupper. ${ }^{38}$ The latter also demonstrated that patients with a higher level of vocational integration at program termination were characterized by higher levels of functioning during the rehabilitation process. In a prospective and controlled evaluation study, Brieger and coworkers ${ }^{34}$ compared a group of psychiatric patients that participated in a comprehensive vocational rehabilitation program with a group of patients without rehabilitation. Both groups were assessed prospectively. Rehabilitation patients were examined at admission into rehabilitation, during the course of the program (about six months after admission), at program termination (about 12 months after admission), and at a 9-month follow-up. They found that the rehabilitation group had similar levels of functioning at the time of admission to the program as the patients without rehabilitation. However, during the course of rehabilitation, the participants were able to increase their functioning level and were significantly superior to the patients without rehabilitation at the end of the program, as well as nine months after program termination.

In predicting the functional level, a high percentage $(50 \%)$ of explained variance was obtained only by negative symptoms. ${ }^{40}$ Brieger and coworkers ${ }^{34}$ showed that the functional level was -besides a measure of premorbid adjustment-mainly predicted by the current psychopathology. The change of the functional level was generally influenced by the level of negative, general and positive symptoms which explained up to $40 \%$ of the variance. Also Watzke ${ }^{29}$ showed that a measure of change in symptoms was the strongest predictor for the change of functional level during rehabilitation as well as for the functional level at a 3-month follow-up. Altogether, this quite impressive influence of psychopathological symptoms on functional outcome indicates that contrary to the assumptions of Anthony and Jansen, ${ }^{25}$ symptoms cannot be neglected in the consideration of potential predictors of rehabilitation success.

Anthony and Jansen's assumption, often cited, issues from a period when most studies on effectiveness of rehabilitation were based on samples of schizophrenic subjects. ${ }^{41}$ Nowadays, subjects with schizophrenia are less frequently represented in rehabilitation samples than in the 1970s and 1980s. In a current study by Brieger 
and coworkers, ${ }^{34}$ only about $30 \%$ of the patients suffered from schizophrenia or schizoaffective disorders. Considering this, elaborate rating scales should be used, to ensure the appropriate evaluation of symptoms. Such scales should also cover symptom changes as confirmed by Eikelmann and Reker. ${ }^{42}$ Finally, the importance of symptoms for the improvement of the general and social functioning level indicates an urgent need for integration of psychiatric and psychotherapeutic services into vocational rehabilitation programs. Pfammatter, Hoffmann, Kupper and Brenner ${ }^{43}$ assume that in mental health services, prevention, acute treatment, and rehabilitation must not be separated but work together very closely. Furthermore, Engels ${ }^{44}$ emphasizes that particularly programs of psychosocial rehabilitation attained their importance due to integration of psychiatric services as well as psychotherapeutic support and work therapy.

\section{Evaluation and prediction of patient-reported outcome measures}

During the past decade, psychiatric research paid increasing attention to the subjective appraisals of the patients. Increasingly, the individually experienced quality of life served as an evaluation criterion of psychiatric interventions. ${ }^{45}$ Persons with severe mental disorders show lower levels of subjective quality of life in comparison to healthy controls. ${ }^{46}$ Competitively employed patients with schizophrenia report a higher quality of life (QOL) than their unemployed counterparts. ${ }^{47}$ Participation in vocational rehabilitation has a positive influence on the subjective QOL..$^{48,49}$ Sellwood and coworkers ${ }^{50}$ found a greater improvement of QOL within a patient group with individual vocational rehabilitation than in a hospital based patient group. That vocational rehabilitation promotes higher levels of subjectively rated QOL has also been shown by Brieger and coworkers. ${ }^{34}$ In their study, even at the time of admission to the program, rehabilitation participants significantly differed from a matched control group regarding their subjective psychological wellbeing. At program termination as well as at the 9-month follow-up, participants still had significantly higher QOL than the control group. Participation in rehabilitation was also associated with more desirable ratings in other patient-reported outcome measures such as lower self-rated anxiety and self-rated depression. ${ }^{34}$

Watzke ${ }^{29}$ showed that, in a sample of patients with schizophrenia, psychological wellbeing at the beginning of a comprehensive vocational rehabilitation program was predicted by the level of general and positive symptoms and the level of premorbid education. These variables explained about $40 \%$ of the variance. The change of psychological wellbeing during the rehabilitation process was predicted by the change of general and negative symptoms. The levels of general and negative symptoms also predicted the final assessment of wellbeing at a 3-month follow-up and explained $30 \%$ of the variance.

\section{Evaluation and prediction of work capabilities}

Impairment of work performance is one of the defining criteria of psychiatric illnesses ${ }^{51}$ As deficits of the disorder, these impairments can last for years without improvement. ${ }^{3}$ Even prior to re-entering the labor market, major goals of vocational rehabilitation programs are to strengthen the clients' work-related skills. ${ }^{52,53}$ Accordingly, the training and development of social and work skills have moved into the focus of rehabilitation programs. Since work capability is assumed to be changeable in the course of rehabilitation and can be assessed independently from general employment rates, it is well suited to serve as an evaluation criterion of rehabilitation success.

Assessment tools for work capability allow a comprehensive screening of individual performance in work related situations including ratings of basic work skills (e.g. punctuality and accuracy) as well as work adjustment, planning skills, work quality and quantity, social aspects of work (e.g. relations with co-workers and superiors, social behavior at work), and communicational skills. Furthermore, these tools assess cognitive performance such as task learning, task memory, and attention.

Although improvement of work skills is one of the main targets of rehabilitation programs, there are only limited scientific studies examining the course of work performance during vocational rehabilitation. Watzke and coworkers ${ }^{54}$ found a general increase in work capability in a vocational rehabilitation sample; especially work related "Learning ability" and "Social communication skills" revealed to be improvable as early as the first months of a comprehensive rehabilitation program. In two earlier reports, ${ }^{53,55}$ improvement in the domains "Social skills" and "Personal presentation" was observed over 17 weeks of work rehabilitation. In a study by Bell and Bryson, ${ }^{52}$ on each of five domains of work (Cooperativeness, Work habits, Work quality, Social skills, Personal presentation), 76 to $91 \%$ of the subjects reached proficiency or improved significantly in a 26-week rehabilitation program. These results indicate that in spite of a general improvement in the total sample, not all subjects equally profit from voca- 
tional rehabilitation regarding improvement of work performance. Watzke, Galvao, Gawlik, Huehne and Brieger ${ }^{56}$ identified patient groups with different courses of work capability. They found distinct patterns of poor, moderate, improving and superior work performance during vocational rehabilitation. While superior work capabilities were mainly found in patients with mood disorders or anxiety disorders, participants with schizophrenia and low education showed unfavorable change in work skills. Affiliation to a specific cluster was also related to reintegration success. About $60 \%$ of the patients with consistent superior work capability expected employment after program termination. In the group with initially low, but improving work capability, about $39 \%$ still expected employment, whereas in the moderate group without improvement about $27 \%$ did, and in the group with constantly poor performance, only $17 \%$ anticipated a favorable reintegration outcome. Likewise, Anthony and coworkers ${ }^{35}$ showed that subjects who found employment after rehabilitation had undergone significant improvement of work skills during rehabilitation, whereas subjects who stayed unemployed did not experience such an increase. These findings are consistent with the assumptions of Anthony and Jansen ${ }^{25}$ that work performance during rehabilitation is one of the best predictors of future employment. General work behavior assessed during the rehabilitation process predicted employment status six months after rehabilitation ${ }^{36}$ as well as total duration of employment, total job earnings ${ }^{57}$ and future functioning at work. ${ }^{21}$

Good initial work capabilities were predicted by good premorbid adjustment, high fluid intelligence, and extroversion. ${ }^{34}$ Suffering from schizophrenia indicated a lower level of work performance at entry into a rehabilitation program as well as at program termination. A positive change in work capability throughout the course of rehabilitation was predicted by a favorable development in symptom status. Again, this result emphasizes the importance of psychopathology for the outcome of vocational rehabilitation. ${ }^{34}$

\section{The role of cognition in predicting rehabilitation success}

As explained above, rehabilitation success is predictable by premorbid social functioning, ${ }^{33,34}$ premorbid intelligence, ${ }^{21,37}$ education level, ${ }^{13}$ duration of pre-rehabilitation unemployment or disintegration, ${ }^{34,37}$ illness related variables such as a late onset and a short duration of the illness, ${ }^{13}$ and symptoms (especially negative symptoms of schizophrenia). ${ }^{15,21,29,34,40}$

However, the predictive value of these variables remains unsatisfactory. Moreover, the growing empiri- cal evidence on the consequences of cognitive deficits of mental disorders has not been sufficiently considered in rehabilitation research.

Neurocognitive deficits are widely recognized as central features of schizophrenia ${ }^{58,59}$ and represent stable characteristics of the disease. ${ }^{60}$ Particularly impaired domains of cognitive functioning amongst patients with schizophrenia are executive functions, working memory, verbal and visual memory and learning, and attention. ${ }^{61}$ These deficits have been shown to be present in first-episode patients who are antipsychotic naive, ${ }^{62}$ as well as in patients in clinical remission and in the active symptomatic state. ${ }^{63}$

Cognitive dysfunctions were found in a broad range of mental disorders other than schizophrenia. Moritz and coworkers ${ }^{64}$ showed that in obsessive compulsive disorder, major depression, and schizophrenia, deficits exist in a wide range of cognitive functions. They argued that these deficits possibly represent a more general rather than specific vulnerability to psychiatric illnesses.

Studies of subjects with bipolar disorder particularly revealed neurocognitive deficits in many of the same cognitive domains that have previously been reported to be abnormal in patients with schizophrenia. ${ }^{65}$ Recent studies suggest that cognitive deficits represent persistent deficits associated with the illness and occur in depressed, manic and hypomanic bipolar patients, as well as in periods of euthymia and remission. 66,67 Independent from psychiatric symptoms, comorbid diagnoses or medication status, the performance of bipolar patients is consistently worse than that of healthy volunteers in learning and sorting tasks, as well as in tests that include a working memory component. ${ }^{68}$

Impairments in cognitive functioning result in immense consequences for adaptive skills ${ }^{69,70}$ and are highly relevant for everyday functioning ${ }^{71}$ as well as for occupational outcome in schizophrenia. ${ }^{28,72}$ Correspondingly, significant correlations between cognitive performance and the duration of employment after vocational rehabilitation were found. ${ }^{73}$ However, studies produced varying results regarding the association between integration into employment and cognitive performance. While some authors showed specific relations between cognition (especially learning, memory, and executive functions) and competitive employment, ${ }^{74}$ others failed to show such associations. ${ }^{75}$ Restrictively, it has to be mentioned that most studies on cognition and rehabilitation or functional outcome were conducted on patients suffering from schizophrenia. Studies on the association between functional outcome and cognition including patients with other mental disorders are rare. Thus, studies referred to in the following paragraphs mainly examined schizophrenic samples. 
Regarding the progress on the level of vocational integration, several studies showed a close relation between verbal and visual memory, executive functioning, word fluency, and intelligence and the level of vocational integration. ${ }^{58,76}$ Executive functions predicted the patients' work attendance/absence. ${ }^{77}$ Cognitive deficits proved to be better predictors of the functional level than the current levels of positive or negative symptoms of schizophrenia. ${ }^{78}$ Additionally, the relation between cognitive functioning and the functional level was significant even after controlling for the influence of negative symptom severity ${ }^{79}$ Likewise, social skills were predicted by cognition. ${ }^{55}$ Regarding work capability measures, task orientation was significantly predicted by executive functions. ${ }^{80}$ In a study by Bryson, Bell, Kaplan and Greig ${ }^{81}$ a significant correlation between general work performance and verbal memory was found. Improvement in work performance was predicted by measures of memory, attention, and executive functions. ${ }^{52}$

This short overview demonstrated that the individual cognitive performance has a great influence on the different domains of rehabilitation success.

Still, most studies on cognition predicting social and vocational functioning have evaluated stable cognitive abilities. ${ }^{82}$ Different to this and based on research using Dynamic Assessment, ${ }^{83,84}$ Green and coworkers ${ }^{72}$ considered "learning potential" as a mediator between basic cognition and functional outcome and called for "a fundamental shift in assessment: from what the individual currently knows to what the individual is capable of learning". Dynamic assessment ${ }^{83,85}$ is a diagnostic approach where specific behavioral interventions are included into cognitive testing procedures and thus, turn these instruments into learning or training tests. Changes in individual performance on dynamic tests reflect the individual's cognitive modifiability or learning potential. Dynamic testing promises to provide clinically helpful diagnostic information in addition to tests of basic neurocognition. Correspondingly, Watzke and coworkers ${ }^{86}$ demonstrated that individual learning potential had prognostic validity for rehabilitation outcome, especially for the longitudinal development of work-related learning ability during rehabilitation, for the development of the functional level beyond rehabilitation and the level of vocational integration after program termination. Generally, patients without cognitive deficits had better rehabilitation outcome in all assessment points and all outcome measures. In fact, patients with remediable cognitive deficits or good learning potential ("learners" according to dynamic assessment) and patients with low learning potential or "stubborn" deficits ${ }^{87}$ ("nonlearners" in the terms of dynamic assessment) had similar starting points at the beginning of the rehabilitation. However, learners turned out to benefit more from vocational rehabilitation while nonlearners showed a rather unfavorable rehabilitation outcome.

Therefore, dynamic assessment of cognitive functions seems to be a forward-looking diagnostic tool with high prognostic validity. It could be useful for the selection of appropriate rehabilitation programs for patients with different levels of cognitive deficits and thus, different levels of needs. Using the knowledge on the influence of cognition and cognitive modifiability on rehabilitation success could help to ensure appropriate assistance, particularly for subjects with poorer performance.

\section{Conclusions on the feasibility of vocational rehabilitation in subjects with severe mental illnesses}

Patients with severe mental disorders are likely to experience a functional decline due to their disease. Functional impairment can lead to job loss and vocational disintegration. Exclusion from work promotes further deterioration due to the illness.

Integration into work has multiple positive effects on the course of the illness and the functional and social wellbeing of psychiatric patients. Therefore, vocational rehabilitation represents an important element within the mental health service system.

What can we learn from research about the feasibility of vocational rehabilitation? What do we need to know in order to increase the likelihood of rehabilitation success?

First of all, a differentiated rehabilitation system is needed to provide support for patients with different needs and capabilities. Not all patients can be expected to profit from one and the same rehabilitation approach. For patients with high performance and less impairment, rehabilitation facilities with a focus on the reintegration into competitive employment as soon as possible during the rehabilitation process are needed. For those patients, programs of supported employment offer the opportunity to rapidly overcome their disintegration and to find their way back into society.

Patients with considerable impairments need rehabilitation that allows them to compensate their deficits. During the program, they need assistance to develop realistic goals regarding their social and vocational future. Support has to be provided to handle social, interactional, and vocational problems. Training in communication and social competencies, as well as the improvement of cognitive functions need to be of- 
fered. The authors believe that psychosocial rehabilitation programs and transitional employment supplying comprehensive support best meet those patients' needs and abilities.

Patients with strong deficits that withdraw from the efforts of those approaches obviously require more sweeping and sustained support as provided by "errorless learning" ${ }^{88}$ Errorless learning represents a rehabilitation technique that provides "prosthetic" compensation strategies for patients with persisting impairments. Work tasks are subdivided into their smallest components. At first, patients start to learn the most simple task component, and thus are very likely to succeed. Training continues with a sequence of task components with complexity increasing in small steps. The execution of each single step is carried out repeatedly and is permanently reinforced. Because of that, the experience of making errors is maximally reduced, while the experience of success is promoted. During the whole training, intense support and repeated instructions are made available. This "prosthesis" is maintained until the work task is transferred to the behavioral repertoire of the patient. This approach promises to offer also vocational rehabilitation to severely impaired patients. Accordingly, Sergi and coworkers ${ }^{89}$ reported that patients with persisting deficits had better rehabilitation success under errorless learning $v s$. standard rehabilitation.

To identify the individual rehabilitation potential and to select an appropriate program, dynamic assessment can be a first, but not the single, diagnostic tool, as proposed by Watzke and coworkers. ${ }^{86}$

However, as described above, rehabilitation success has to be examined multidimensionally and must not be reduced to the mere integration into competitive employment. Beyond reintegration into competitive employment, rehabilitation success should also be seen on the level of vocational integration, strengthening of work capabilities, improvement on the functional level, and a better quality of life.

Knowing about the differential aspects of rehabilitation success also provides greater access to the different prognostic factors that contribute to the attainment of a favorable rehabilitation outcome.

The fact that variables like pre-rehabilitation unemployment and disintegration ${ }^{34,37}$ are important predictors of rehabilitation success indicates the urgency of early recognition of the patient's rehabilitation needs. This, again, emphasizes the importance of understanding rehabilitation to be an integral component of the mental health system. The finding that a short duration of the illness also has prognostic validity in predicting rehabilitation success points into the same direction. Rehabilitation need has to be recognized as early as pos- sible within the course of the illness and also as early as possible within every single illness episode to shorten the time of the patient's disintegration and to avoid periods of stagnation.

Therefore, clinicians, psychologists, and social workers have to work closely together to ensure an early transfer from the clinic to the appropriate rehabilitation program.

Findings of the prognostic significance of symptoms for rehabilitation success refer to the importance of the integration of psychiatric and psychotherapeutic services and programs of vocational rehabilitation. Rehabilitation must start within the clinic; psychiatric help must continue during the rehabilitation. Additionally, psychiatric treatment of the symptoms during rehabilitation prevents an exacerbation of the illness, which could be a determining factor of premature termination of the patient's participation in the program. ${ }^{90}$

During the program, a consecutive evaluation of the patient's development regarding his or her functional level, work capability, and subjective wellbeing also has to take place. This procedure helps to diagnose the patient's individual needs and abilities and therefore ensures the appropriate support for the patient. Consequently, favorable courses of work capability, social and general functioning were reported to significantly predict successful reintegration into work.

Therefore, training for cognition and for social skills should be integrated into rehabilitation programs to compensate for individual deficits. These aspects of promotion of a successful rehabilitation can be summarized as follows:

1. Early recognition of the individual's need for rehabilitation.

2. Rehabilitation as an integral part of the mental health system.

3. Close collaboration between clinics and rehabilitation facilities.

4. The rehabilitation system involving programs of different degrees of complexity to meet the patients' abilities and needs.

5. Psychiatric care integrated into rehabilitation to prevent illness exacerbation and premature program termination.

6. Multidimensional and consecutive evaluation of rehabilitation success.

7. Integration of trainings for social skills and cognition integrated into the program to compensate for deficits of prognostic validity.

Altogether, a broader discussion within society is needed to promote the integration of individuals with 
mental disorders. Illness-related stigmata must be overcome and the acceptance of patients with mental disorders despite and because of their deficits should be encouraged.

\section{References}

I. Baron RC, Salzer MS.Accounting for unemployment among people with mental illness. Behav Sci Law 2002; 20:585-599.

2. Beiser M, Bean G, Erickson D, Zhang J, lacono WG, Rector NA.

Biological and psychosocial predictors of job performance following a first episode of psychosis. Am J Psychiatry 1994; 151:857-863.

3. Carone BJ, Harrow M, Westermeyer JF. Posthospital course and outcome in schizophrenia. Arch Gen Psychiatry 1991; 48:247-253. 4. Marneros A, Deister A, Rohde A. Comparison of long-term outcome in schizophrenic, affective and schizoaffective disorders. Br J Psychiatry 1992; |61:44-5|.

5. Marneros A, Deister A, Rohde A. Psychopathological and social status of patients with affective, schizophrenic and schizoaffective disorders after long-term course. Acta Psychiat Scand 1990; 82:352-358.

6. Marwaha S, Johnson S. Schizophrenia and employment - A review. Soc Psych Psych Epid 2004; 39:337-349.

7. Boardman J, Grove B, Perkins R, Shepherd G. Work and employment for people with psychiatric disabilities. Br J Psychiatry 2003; 182:467-468. 8. Kates N, Greiff BS, Hagen DQ. The psychological impact of job loss. Washington:American Psychiatric Press, 1990.

9. Wing JK, Brown GW. Institutionalism and Schizophrenia:A comparative study of three mental Hospitals 1960-1968. Cambridge: University Press, 1970.

10. Pritchard C. Is there a link between suicide in young men and unemployment? A comparison of the UK with other European Community Countries. Br J Psychiatry 1992; 160:750-756.

II. Bromberger JT, Matthews KA. Employment status and depressive symptoms in middle-aged women:A longitudinal investigation. Am J Public Health 1994; 84:202-206.

12. Brieger P, Bloeink R, Roettig S, Marneros A. Disability payments due to unipolar depressive and bipolar affective disorders [Die vorzeitige Berentung von unipolar depressiv und bipolar affektiv Erkrankten]. Psychiat Prax 2004; 31:203-206.

13. Reker T.Work Rehabilitation in Psychiatry [Arbeitsrehabilitation in der Psychiatrie]. Darmstadt: Steinkopff, 1998.

14. Roessler W. Psychiatric rehabilitation today: an overview. World Psychiatry 2006; 5:15I-157.

15. Cook JA, Razzano L.Vocational rehabilitation for persons with schizophrenia: Recent research and implications for practice.

Schizophrenia Bull 2000; 26:87-103.

16. Craig T.What is psychiatric rehabilitation? In: Roberts G, Davenport S, Holloway F, Tattan T, eds. Enabling Recovery:The Principles and Practice of Rehabilitation Psychiatry. London: Gaskell (Royal College of Psychiatrists), 2006:3-15.

17. Bond GR, Drake RE, Mueser KT, Becker DR. An update on supported employment for people with severe mental illness. Psychiatr Serv 1997; 48:335-346.

18. Becker DR, Drake RE.A Working Life:The Individual Placement and Support (IPS) Program. Concord, NH: New Hampshire-Dartmouth Psychiatric Research Center, 1993.

19. Crowther R, Marshall M, Bond G, Huxley P.Vocational rehabilitation for people with severe mental illness (Cochrane-Review). In:The Cochrane Library. Oxford: Update Software, 2003:
20. McGurk SR, Mueser KT. Cognitive functioning, symptoms, and work in supported employment:A review and heuristic model. Schizophr Res 2004; 70:147-173.

21. Hoffmann H, Kupper Z, Zbinden M, Hirsbrunner HP. Predicting vocational functioning and outcome in schizophrenia outpatients attending a vocational rehabilitation program. Soc Psychiatry Psychiatry Epidemiol 2003; 38:76-82.

22. Liberman RP, Kopelowicz A,Ventura J, Gutkind D. Operational criteria and factors related to recovery from schizophrenia. Int Rev Psychiatr 2002; 14:256-272.

23. Morgan R, Cheadle AJ. Unemployment impedes resettlement. Soc Psychiatry 1975; 10:63-67.

24. Norquist GS. Role of outcome measurement in psychiatry. In: Ishak WW, Burt T, Sederer LI, eds. Outcome measurement in psychiatry:A critical review. Washington:American Psychiatric Publishing, Inc., 2002:3-13. 25. Anthony WA, Jansen MA. Predicting the vocational capacity of the chronically mentally ill. Research and policy implications. Am Psychol 1984; 39:537-544

26. Lehman AF.Vocational rehabilitation in schizophrenia. Schizophrenia Bull 1995; 21:645-656.

27. Ciompi L,Ague C, Dauwalder JP.A research program on the rehabilitation of the mentally ill. I. Concepts and methodologic problems [Ein Forschungsprogramm ueber die Rehabilitation psychisch Kranker: I. Konzepte und methodologische Probleme]. Nervenarzt 1977; 48:12-18. 28. Watzke S, Brieger P. Neuropsychological testing in vocational rehabilitation for subjects with schizophrenia [Neuropsychologische Diagnostik in der beruflichen Rehabilitation schizophrener Menschen]. Fortschr Neurol Psychiat 2004; 72:643-65I.

29. Watzke S. Berufliche Rehabilitation schizophren Erkrankter - Erfolgsvorhersage durch Indikatoren kognitiver Modifizierbarkeit. Hamburg:Verlag Dr. Kovac, 2006.

30. FDA. Innovation or Stagnation: Challenge and Opportunity on the Critical Path to New Medical Products. FDA, US Department of Health and Human Services, Food and Drug Administration, 2004.

3I. Drake RE, McHugo GJ, Becker DR,Anthony WA, Clark RE. The New Hampshire study of supported employment for people with severe mental illness.J Consult Clin Psychol 1996;64:391-399.

32. Jaeger J, Douglas E. Neuropsychiatric rehabilitation for persistent mental illness. Psychiat Quart 1992; 63:71-94.

33. Mueser KT, Salyers MP, Mueser PR.A prospective analysis of work in schizophrenia. Schizophrenia Bull 200I; 27:28I-296.

34. Brieger P,Watzke S, Galvao A, Huehne M, Gawlik B.Vocational rehabilitation and integration for the mentally ill: How does it work? [Wie wirkt berufliche Rehabilitation und Integration psychisch kranker Menschen?]. Bonn: Psychiatrie-Verlag, 2006.

35. Anthony WA, Rogers ES, Cohen M, Davies RR. Relationship between psychiatric symptomatology, work skills, and future vocational performance. Psychiatr Serv 1995; 46:353-358.

36. Rogers ES, Anthony WA, Cohen MR, Davies R. Prediction of vocational outcome based on clinical and demographic indicators among vocationally ready clients. Community Ment Health J 1997; 33:99-I 2.

37. Dauwalder HP, Ciompi L,Aebi E, Hubschmid T.A research program for the rehabilitation of psychiatric patients. IV. Study of the role of future expectations of chronic schizophrenics [Ein Forschungsprogramm zur Rehabilitation psychisch Kranker - Untersuchung zur Rolle von Zukunftserwartungen bei chronisch Schizophrenen]. Nervenarzt 1984; 55:257-264.

38. Hoffmann H, Kupper Z. Patients dynamics in early stages of vocational rehabilitation:A pilot Study. Compr Psychiat 1996; 37:216-221.

39. Ferdinandi AD, Yoottanasumpun V, Pollack S, Bermanzohn PC. Rehab Rounds: Predicting rehabilitation outcome among patients with schizophrenia. Psychiatr Serv 1998; 49:907-909. 
40. Hoffmann H, Kupper Z, Kunz B. Predicting schizophrenic outpatients' behavior by symptomatology and social skills.J Nerv Ment Dis 1998; I86:2|4-222.

4I. Marshall M, Crowther R,Almaraz-Serrano A, Creed F, Sledge W, Kluiter H, Roberts C, Hill E,Wiersma D, Bond GR, Huxley P, Tyrer P. Systematic review of the effectiveness of day care for people with severe mental disorders: (I) Acute day hospital versus admission; (2) Vocational rehabilitation; (3) Day hospital versus outpatient care. Health Technol Assess 200I; 5: I-65.

42. Eikelmann B, Reker T. Rehabilitation psychisch Behinderter in den Werkstaetten fuer Behinderte? Fakten, Ergebnisse, Empfehlungen. Krankenhauspsychiatrie 1994; 5:66-70.

43. Pfammatter M, Hoffmann H, Kupper Z, Brenner HD.Vocational rehabilitation in chronic mental illness. The current position [Arbeitsrehabilitation bei chronisch psychisch Kranken - Eine Standortbestimmung]. Fortschr Neurol Psychiat 2000; 68:61-69. 44. Engels D. Medical and occupational rehabilitation of psychiatric patients. Results of concomitant research of rehabilitation facilities for psychiatric and handicapped patients [Medizinische und berufliche Rehabilitation fuer psychisch Kranke. Ergebnisse der Begleitforschung von Rehabilitationseinrichtungen fuer psychisch Kranke und Behinderte (RPK)]. Rehabilitation 1993; 32:227-23 I.

45. Brieger P, Roettig S, Marneros A. Quality of life in unipolar depressive and bipolar affective patients [Lebensqualitaet bei unipolar depressiven und bipolar affektiven Patienten]. Psychiat Prax 2004; 31:304-309. 46.WHOQOL-Group. Development of the World Health Organization WHOQOL-BREF quality of life assessment. Psychol Med 1998; 28:55I-558. 47. Chan S,Yu IW. Quality of life of clients with schizophrenia.J Adv Nurs 2004; 45:72-83.

48. Bond GR, Resnick SG, Drake RE, Xie HY, McHugo GJ, Bebout RR. Does competitive employment improve nonvocational outcomes for people with severe mental illness? J Consult Clin Psych 200I;69:489-50I. 49. Holzner B, Kemmler G, Meise U.The impact of work-related rehabilitation on the quality of life of patients with schizophrenia. Soc Psychiatry Psichiatr Epidemiol 1998; 33:624-631.

50. Sellwood W, Thomas CS, Tarrier N, Jones S, Clewes J, James A, Welford M, Palmer J, McCarthy E.A randomised controlled trial of home-based rehabilitation versus outpatient-based rehabilitation for patients suffering from chronic schizophrenia. Soc Psychiatry Psichiatr Epidemiol 1999; 34:250-253.

51.American Psychiatric Association. Diagnostic and statistical Manual of Mental Disorders, Fourth Edition. Washington, D.C.:American Psychiatric Association, 1994.

52. Bell M, Bryson G. Work rehabilitation in schizophrenia: Does cognitive impairment limit improvement? Schizophrenia Bull 200 ; 27:269-279. 53. Lysaker P, Bell M. Work performance over time for people with schizophrenia. Psychosoc Rehabil J 1995; 18: 141-145.

54. Watzke S, Galvao A, Gawlik B, Huehne M, Brieger P. Capability to work in vocational rehabilitation of the severe mentally ill: initial predictors and change after six months [Auspraegung und Veraenderung der Arbeitsfaehigkeiten psychisch kranker Menschen in der beruflichen Rehabilitation]. Psychiat Prax 2005; 32:292-298.

55. Lysaker P, Bell M, Bioty SM. Cognitive deficits in schizophrenia. Prediction of symptom change for participators in work rehabilitation. J Nerv Ment Dis 1995; 183:332-336.

56. Watzke S, Galvao A, Gawlik B, Huehne M, Brieger P. Change in work performance in vocational rehabilitation for subjects with severe mental illness - distinct responder groups. Int J Soc Psychiatry 2006;52:309-323. 57. Bond GR, Friedmeyer MH. Predictive validity of situational assessment at a psychiatric rehabilitation agency. Psychosoc Rehab J 1987; | I:6I-77. 58. Bellack AS, Gold JM, Buchanan RW. Cognitive rehabilitation for schizophrenia: Problems, prospects, and strategies. Schizophrenia Bull 1999; 25:257-274
59. Morice R, Delahunty A. Frontal/executive impairments in schizophrenia. Schizophrenia Bull 1996;22:125-I37.

60. Goldberg TE, Greenberg RD, Griffin SJ, Gold JM, Kleinmann JE, Pickar D, Schulz SC,Weinberger DR. The effect of Clozapine on cognition and psychiatric symptoms in patients with schizophrenia. Br J Psychiatry 1993; 162:43-48.

61. Green MF, Nuechterlein KH, Gold JM, Barch DM, Cohen J, Essock S, Fenton WS, Frese F, Goldberg TE, Heaton RK, Keefe RSE, Kern RS, Kraemer H, Stover E, Weinberger DR, Zalcman S, Marder SR. Approaching a consensus cognitive battery for clinical trials in schizophrenia:The NIMH-MATRICS conference to select cognitive domains and test criteria. Biol Psychiat 2004; 56:30I-307.

62. Bilder RM, Goldman RS, Robinson D, Reiter G, Bell L, Bates JA, Pappadopulos E,Willson DF,Alvir JM,Woerner MG, Geisler S, Kane JM, Lieberman JA. Neuropsychology of first-episode schizophrenia: initial characterization and clinical correlates. Am J Psychiatry 2000; 157:549-559. 63. Gold JM, Green MF. Neurocognition in Schizophrenia. In: Kaplan HI, Sadock BJ, eds. Kaplan and Sadock's Comprehensive Textbook of Psychiatry. Baltimore: Lippincott, Williams \& Wilkins, 2005: I 426-I 448. 64. Moritz S, Birkner C, Kloss M, Jahn H, Hand I, Haasen C, Krausz $M$. Executive functioning in obsessive-compulsive disorder, unipolar depression, and schizophrenia. Arch Clin Neuropsych 2002; 17:477-483. 65. Altshuler LL,Ventura J, van GorpWG, Green MF,Theberge DC, Mintz J. Neurocognitive function in clinically stable men with bipolar I disorder or schizophrenia and normal control subjects. Biol Psychiatry 2004; 56:560-569.

66. Martinez-Aran A,Vieta E, Reinares M, Colom F, Torrent C, SanchezMoreno J, Benabarre A, Goikolea JM, Comes M, Salamero M. Cognitive function across manic or hypomanic, depressed, and euthymic states in bipolar disorder. Am J Psychiatry 2004; 161:262-270.

67. Gildengers AG, Butters MA, Seligman K, McShea M, Miller MD, Mulsant $\mathrm{BH}$, Kupfer DJ, Reynolds CF, 3rd. Cognitive functioning in late-life bipolar disorder.Am J Psychiatry 2004; 161:736-738.

68. Basso MR, Lowery N, Neel J, Purdie R, Bornstein RA.

Neuropsychological impairment among manic, depressed, and mixedepisode inpatients with bipolar disorder. Neuropsychology 2002; 16:84-91. 69. Delahunty A, Morice R. Rehabilitation of frontal/executive impairments in schizophrenia. Aust N Z J Psychiatry 1996; 30:760-767.

70.Velligan DI, Mahurin RK, Diamond PL, Hazleton BC, Eckert SL, Miller AL.The functional significance of symptomatology and cognitive function in schizophrenia. Schizophr Res 1997; 25:21-31.

7I. Green MF, Kern RS, Heaton RK. Longitudinal studies of cognition and functional outcome in schizophrenia: Implications for MATRICS. Schizophr Res 2004; 72:4I-5I.

72. Green MF, Kern RS, Braff DL, Mintz J. Neurocognitive deficits and functional outcome in schizophrenia:Are we measuring the "right stuff"? Schizophrenia Bull 2000;26:1 I9-136.

73. Gold JM, Goldberg RW, McNary SW, Dixon LB, Lehman AF. Cognitive correlates of job tenure among patients with severe mental illness. Am J Psychiatry 2002; I59:1395- I 402.

74. McGurk SR, Mueser KT, Harvey PD, LaPuglia R, Marder J. Cognitive and symptom predictors of work outcomes for clients with schizophrenia in supported employment. Psychiatr Serv 2003; 54: I I29- I I 35.

75. Mueser KT, Becker DR, Torrey WC, Xie H, Bond GR, Drake RE, Dain $B$ J.Work and nonvocational domains of functioning in persons with severe mental illness:A longitudinal analysis. J Nerv Ment Dis 1997; 185:419-426. 76. Brekke JS, Raine A,Ansel M, Lencz T. Neuropsychological correlates of psychosocial functioning in schizophrenia. Schizophrenia Bull 1997; 23:19-28.

77. Heinrichs RW, Bury AS. Selected neurocognitive test data and work attendance for chronic psychiatric patients. Percept Mot Skills 1992; 75:1027-1032 
78. Harvey PD, Howanitz E, Parrella M,White L, Davidson M, Mohs RC, Hoblyn J, Davis KL. Symptoms, cognitive functioning, and adaptive skills in geriatric patients with lifelong schizophrenia:A comparison across treatment sites. Am J Psychiatry 1998; I55:1080-1087.

79. McGurk SR, Moriarty PJ, Harvey PD, Parrella M, White L, Friedman J, Davis KL. Relationship of cognitive functioning, adaptive life skills, and negative symptom severity in poor-outcome geriatric schizophrenia patients. J Neuropsychiatry Clin Neurosci 2000; 12:257-264.

80. Lysaker P, Bell M, Beam-Goulet J.Wisconsin Card Sorting Test and work performance in schizophrenia. Psychiatry Res 1995; 56:45-5I.

8I. Bryson G, Bell MD, Kaplan E, Greig T.The functional consequences of memory impairments on initial work performance in people with schizophrenia.J Nerv Ment Dis 1998; 186:610-615.

82. Green MF.What are the functional consequences of neurocognitive deficits in schizophrenia? Am J Psychiatry 1996; 153:32 I-330.

83. Guthke J,Wiedl KH. Dynamic Testing - Psychodiagnostics of intraindividual Variability [Dynamisches Testen - Zur Psychodiagnostik der intraindividuellen Variabilitaet]. Goettingen: Hogrefe, 1996.

84.Wiedl KH. Rehab Rounds: Cognitive modifiability as a measure of readiness for rehabilitation. Psychiatr Serv 1999; 50:14I I-1413, I4I9.
85. Grigorenko EL, Sternberg RJ. Dynamic testing. Psychol Bull 1998; I24:75-III.

86. Watzke S, Brieger P, Schoettke H,Wiedl KH. Learning potential predicting rehabilitation outcome in schizophrenia. Eur Arch Psychiatry Clin Neurosci in press;

87. Green MF, Satz P, Ganzell S, Vaclav JF.Wisconsin Card Sorting Test performance in schizophrenia: Remediation of a stubborn deficit.Am J Psychiatry 1992; 149:62-67.

88. Kern RS, Liberman RP, Kopelowicz A, Mintz J, Green MF.Applications of errorless learning for improving work performance in persons with schizophrenia. Am J Psychiatry 2002; 159:1921-1926.

89. Sergi MJ, Kern RS, Mitchell S, Herrera A, Kogler K, Doran D, Green MF. How useful are learning potential assessments in predicting rehabilitation outcome in schizophrenia? Schizophr Res 2003; 60:328.

90. Watzke S, Galvao A, Gawlik B, Huehne M, Brieger P. Early termination of vocational rehabilitation for the severely mentally ill [Maßnahmeabbrecher in der beruflichen Rehabilitation psychisch kranker Menschen]. Psychiat Prax 2006; 33:|24-|3|. 